\title{
Assessment of Variation in Care Following Hospital Discharge for Children with Acute Asthma
}

\author{
Mei Chan' \\ Melinda Gray ${ }^{2}$ \\ Christine Burns ${ }^{2}$ \\ Louisa Owens ${ }^{1,2}$ \\ Adam Jaffe ${ }^{1,2}$ \\ Nusrat Homaira ${ }^{1,2}$ \\ 'Discipline of Paediatrics, School of \\ Women's and Children's Health, Faculty \\ of Medicine, University of New South \\ Wales, Sydney, NSW, 203I, Australia; \\ ${ }^{2}$ Respiratory Department, Sydney \\ Children's Hospital, Randwick, Sydney, \\ NSW, Australia
}

Correspondence: Nusrat Homaira Discipline of Paediatrics, School of Women's and Children's Health, Faculty of Medicine, University of New South Wales, Sydney, NSW, 203I, Australia Tel +6I 293825526

Email n.homaira@unsw.edu.au
Purpose: To evaluate potential variation in care management pathways following hospital discharge for children with asthma in New South Wales, Australia.

Methods: A cross-sectional web-based survey was conducted in emergency departments (EDs) and paediatric units of public hospitals with more than five paediatric beds within New South Wales, Australia, between July 2018 and March 2019. Nursing and medical staff in EDs and paediatric units who had cared for children aged under 18 years with asthma in the preceding 12 months were invited to participate in this study. Outcome measures included use of clinical practice guidelines and asthma action plan (AAP); advice on posthospitalization follow-up; provision of asthma education for parents/carers; availability of community-based asthma services; communication with schools/childcare services.

Results: A total of 502 participants (236 nursing and 266 medical staff, response rate $=22 \%$ ) from 37 hospitals were included. Overall, the use of AAP was not universal (median=90\%; $\mathrm{IQR}=81-96 \%$ ) with significant difference across local health districts (LHDs) $(88.6 \%, 95 \%$ $\mathrm{CI}=85.4-91.3)$ and between EDs and paediatric wards $\left(p=9.4 \times 10^{-9}\right)$; and a range of asthma clinical practice guidelines were used. Post-hospitalization follow-up within 2-3 days was recommended by $70 \%$ of the respondents, but only $8 \%$ reported that hospitals had a system in place to ensure follow-up compliance. Formal asthma education sessions (27\% respondents) were seldom provided to parents/carers during hospital stays, especially in EDs (14\% respondents). Less than $50 \%$ of the respondents were aware of any asthma community services for children and only $4 \%$ reported that schools/childcare services were notified about the child's hospital admission for an asthma flare up.

Conclusion: There are marked variations in the post-hospitalization asthma care and community management for children in NSW. An integrated standardized model of care may improve health outcomes in children with asthma.

Keywords: asthma, children, post-hospitalization, community-based, integrated care

\section{Introduction}

Asthma is a major health issue affecting more than 339 million people worldwide. According to the World Health Organization, more than 400,000 deaths and nearly 25 million disability-adjusted life-years (DALYs) are associated with asthma every year. ${ }^{1}$ In children, asthma is a leading cause of hospital admission and emergency department (ED) attendance. ${ }^{2-5}$ It is a significant burden on the individual, their families and the wider community. Children with asthma-related hospitalization are at increased risk of subsequent admissions with up to $30 \%$ increase in the probability of readmission after each hospitalization. ${ }^{6}$ Approximately $80 \%$ of 
these asthma-related admissions are potentially avoidable if appropriate and evidence-based post-hospitalization care is in place. $^{7}$

According to the Global Initiative for Asthma (GINA) guidelines for asthma management and prevention, in order to improve asthma control, patients with asthma and their carers need to acquire knowledge and skills on the proper use of inhaler devices, an understanding of the different medications, provided with and adhere to an asthma action plan (AAP), self-monitor asthma symptoms and have a regular medical review by primary health care providers/ general practitioners (GPs). ${ }^{8}$ There is ample evidence to suggest that comprehensive or integrated communitybased interventions, including home environmental assessment, self-management education, care coordination, public education and awareness, policies advocacy and primary care providers training, could improve clinical health outcomes, quality of life and reduce unscheduled ED or acute care visits for children with asthma. ${ }^{9-12}$

Regular follow-up with a GP is important for better asthma clinical outcomes and reduced risk of rehospitalization as it provides an opportunity to educate families, assess asthma control, adjust medications, review the AAP and facilitate treatment compliance and adherence. In a study of 729,343 patients with asthma, those with regular clinic visits were found to have their risk of admission to a general ward, ED and intensive care unit for asthma exacerbations reduced by $52 \%, 17 \%$ and $51 \%$, respectively, in comparison to that of infrequent visitors. ${ }^{13}$

School also plays a crucial role in asthma management as children spend a large portion of their time in school each day. It is, therefore, important for school personnel to be aware of any students who have asthma and be trained in asthma management. ${ }^{14}$ Good communication between health care providers and schools, especially after the child is discharged from hospital for an asthma exacerbation, is essential to effective asthma management in school. Currently, there are little data available regarding posthospitalization communication between schools and acute care providers, though a recent survey in the United States revealed that only $30 \%$ of the school teachers were notified when students missed school due to their asthma. ${ }^{15}$

In New South Wales, the public hospital system is divided into 15 local health districts (LHDs) and three specialty health networks that cover more than 230 public hospitals across the state. ${ }^{16}$ Acute hospital care for children is available in all 15 LHDs and one specialty health network, the Sydney Children's Hospitals Network, which comprises the Children's Hospital Westmead and Sydney Children's Hospital Randwick. General practitioners are the main primary care providers in Australia and are the first line of contact after patients are discharged from the hospital.

Asthma, in New South Wales, was the primary diagnosis for nearly 40,000 hospitalizations and about $44 \%$ of these were children aged younger than 14 years old. Although all public hospitals in New South Wales are required to comply with the Ministry of Health clinical practice guidelines, ${ }^{17}$ each hospital has its own local protocol for clinical management. It is unclear whether there is also variation between hospitals or LHDs in their posthospitalization management pathway for children with asthma.

Previous studies, in Australia and other countries, on childhood asthma care have focused on general barriers to asthma management and often from the perspective of parents/carers or primary care providers. ${ }^{18-21}$ To date, few published data are available on the gaps in transition from acute care to the community or post-hospitalization care for children with asthma, especially from the viewpoint of the acute care providers. This study aimed to enhance our understanding of potential contributors to suboptimal childhood asthma care by exploring the gaps and variations in the existing post-discharge management pathway for children with asthma in New South Wales.

\section{Methods}

\section{Study Settings and Participants}

We conducted a cross-sectional survey across all 15 LHDs of New South Wales and the Sydney Children's Hospital Network between July 2018 and March 2019, using an online self-administered questionnaire. Only hospitals with more than five paediatric beds were included in this study. Eligible hospitals were identified by telephoning the administrative staff of individual hospital to confirm the total number of paediatric beds. Participants eligible for the survey included both nursing (ie, registered nurses, clinical nurse educators, clinical nurse specialists, clinical nurse consultant, nurse unit managers, nurse practitioners and enrolled nurses) and medical staff (ie, consultants, staff specialists, career medical officer, medical registrar and medical residents) in EDs and paediatric units, who had cared for children under 18 years with asthma in the preceding 12 months. Those who had not cared for any paediatric patients with 
asthma in the preceding 12 months or worked in outpatient clinics were excluded.

\section{Study Questionnaire}

The online survey consisted of 16 items. The first part of the questionnaire collected information on respondents' location of practice, ie, LHD and department, and their position titles. The remaining questions were designed to evaluate the following domains: 1) use of clinical practice guidelines and AAP, 2) advice on post-hospitalization follow-up asthma review, 3) provision of asthma education for parents/carers during hospital presentations, 4) availability of community asthma care, 5) communication with schools/childcare services after the child was discharged from hospital. In addition, two open-ended questions were included to allow further feedback and comments on existing gaps between hospitals and community in providing integrated asthma care for children. The questionnaire was designed with input from a panel of hospital clinicians (including medical consultants, respiratory specialists, clinical nurse consultants and registered nurses) and information obtained from relevant scientific publications. The questionnaire was pilot tested among 10 paediatric doctors and nurses and modified accordingly with the final version as shown in Appendix 1.

\section{Survey Distribution}

We used web-based Qualtrics software to distribute the online survey, which took about 10-15 minutes to complete. Eligible participants were identified with the assistance of the Nursing Unit Managers, Heads of Department or research administrative staff of the participating hospitals who were also responsible for distributing the online link of the web-based survey to the eligible staff members via their internal staff emails. The online link provided access to participant information sheet and consent options. Participants willing to take part in the survey indicated their consent by ticking the "yes" button on the webpage.

\section{Statistical Analysis}

We descriptively summarized categorical data and presented as absolute frequencies and percentages as appropriate. Comparisons between LHDs and departments (ED vs paediatric ward) were analyzed using $F$-test approximation of the Rao and Scott Chi-square test, ${ }^{22,23}$ which adjusted for the design effect. The upper and lower confidence intervals was estimated by using Clopper-Pearson method. ${ }^{24}$ All statistical tests were two-sided and performed at 5\% level of significance. All statistical analyses were conducted using R program version 4.0.5 for Window.

Free text responses from open-ended questions were input to NVivo (QRS International Pty Ltd., Version 12 Pro) and analyzed thematically as described by Braun and Clarke. ${ }^{25}$ In this analysis, individual responses were read several times to ensure thorough comprehension, and patterns within the data were identified and coded. Data with the same codes were collated and organized into thematic categories, and frequencies of each category were reported.

\section{Sample Size Calculation}

Sample size calculation was calculated based on the assumption that there were 2500 of eligible medical and nursing staff in total across the 37 hospitals. With a response distribution of $50 \%,{ }^{26}$ a sample of 334 was required at $95 \%$ confidence level and a margin of error of $5 \%$.

\section{Ethics Approval}

The study was approved by the Sydney Children's Hospitals Network Human Research Ethics Committee (LNR/18/SCHN/177).

\section{Results}

Overall, 2283 nursing and medical staff from EDs and paediatric wards of 37 eligible public hospitals from 15 LHDs and Sydney Children's Hospitals Network were invited to participate, and a total of 511 responded to the questionnaire. Nine respondents did not care for children with asthma in the preceding 12 months and were excluded from the study. As a result, 502 participants (236 nursing and 266 medical staff) were included in this study (Supplementary Table 1). The overall response rate was $22 \%$ (ranging from $9 \%$ to $43 \%$ ).

\section{Use of Clinical Practice Guideline and Asthma Action Plan}

Nearly all respondents $(97 \%)$ reported that clinical practice guidelines were used in management of asthma exacerbations (Table 1). However, different clinical practice guidelines were used within the same hospital and between different hospitals within the same LHDs (Figure 1). Similarly, approximately $89 \%$ of the respondents reported that AAPs were provided to parents when their child was discharged from hospital, but there was considerable variability across LHDs (95\% CI $=85.4-$ 
91.3); and patients in paediatric wards were more likely to receive an AAP upon their discharge from the hospital (98.1\%; 95\% CI=95.2-99.5) than those in EDs $(80.9 \%$; 95\% CI=75.7-85.5) (Table 1). Furthermore, a variety of AAPs were reported by the respondents to have provided to parents/carers upon their child's hospital discharge (Figure 2).

\section{Follow-Up Review}

Post-discharge asthma follow-up advice was provided to all children with asthma (99.3\%; 95\% CI=98.2-99.8) (Table 1). The follow-up advice was provided as verbal (77\%; 95\% CI=72.5-80.2) and written (73\%; 95\% $\mathrm{CI}=68.3-76.5)$ instructions to parents/carers in addition to a discharge letter provided to the child's GPs $(82 \%$; 95\% CI=78.4-85.4). In most LHDs (75\%; 95\% CI=40.979.4), parents/carers were advised to have their child followed up with their GP within 2-3 days post-discharge from hospital, but in some rural and regional areas, followup appointment could be recommended for $>6$ days posthospitalization. Meanwhile, a post-discharge follow-up within 2-3 days recommendations were more likely to be reported by respondents from EDs $(86 \%$; 95\% CI=81.290.7) than those from paediatric wards $(63 \% ; 95 \%$ $\mathrm{CI}=55.5-69.5)$. Most of the respondents $(81 \%$; $95 \%$ $\mathrm{CI}=77.5-84.6)$ reported that parents/carers were responsible for organizing follow-up review (Table 1) and only $8 \%$ (95\% CI=5.7-11.4) indicated that their hospitals ensured that follow-up appointments were attended (Table 1).

\section{Asthma Education}

Overall, $96 \%$ of the staff across LHDs agreed that asthma education was provided to the parents/carers, with a significantly higher number of staff in the paediatric wards $(99 \%$; 95\% CI=96.5-99.9) than in EDs $(94.3 \%$; 95\% $\mathrm{CI}=90.8-96.8)$ reported to have asthma education given to parents during their child's hospital visits $(p=0.007) \quad$ (Table 1). However, most (86\%; 95\% $\mathrm{CI}=82.4-89.0)$ reported that asthma education was mainly delivered face-to-face casually and only $27 \% \quad(95 \%$ $\mathrm{CI}=22.7-31.1)$ reported having formal education sessions provided to the parents/carers (Table 1). More than $75 \%$ of the respondents reported that adherence to asthma medications, correct asthma device technique, understanding of AAP and recognition of asthma triggers were included in the asthma education provided (Supplementary Table 2). Although $81 \%$ of the respondents reported providing digital/online resources to parents/carers, there was significant difference across LHDs (81\%; 95\% CI=76.6-84.4) and between EDs $(77 \% ; 95 \% \quad \mathrm{CI}=71-82)$ and paediatric wards $(86 \%$; 95\% CI=79.9-90.5) (Table 1).

\section{Community Asthma Services}

Only $45 \%(95 \% \mathrm{CI}=38.4-51.5)$ of the staff surveyed were aware of any community services (eg, post-discharge asthma assessment, home visits, asthma education, etc) for children with asthma in their local areas, with significant variability among LHDs (Table 1 and Figure 3). Community asthma services were believed to be provided by asthma educators (in $64 \%$ of respondents), paediatricians (34\%), community nurses (31\%), GPs (31\%), respiratory specialists $(15 \%)$ or GP practice nurses $(4 \%)$ (Figure 3).

\section{Communication with Schools/Childcare Services}

When children with asthma were discharged from hospitals, only $4.2 \%(95 \% \mathrm{CI}=2.4-6.8)$ of the surveyed staff reported that schools or childcare services were notified, which was consistent practice across LHDs, though, such practice seemed to be more prevalent in paediatric wards $(7 \% ; 95 \% \mathrm{CI}=3.5-12.1)$ than in EDs $(2 \% ; 95 \% \mathrm{CI}=0.5-$ 5.0) (Table 1).

\section{Qualitative Analysis}

A total of 282 participating staff responded to the openended question on their perceived gaps between hospital and community in providing asthma care services for children. Eight major themes and 14 sub-themes emerged from the analysis as summarized in Table 2.

Theme 1: Follow-up review

Of the 282 respondents, $15 \%$ believed that failure of GP follow-up in a timely manner after the child was discharged from asthma-related hospital admissions generated a huge gap in effective asthma management for children. Thirtyeight $(13 \%)$ raised concern about parental non-compliance with the follow-up advices, which could be attributed to cost and accessibility of GP appointments (5\%).

Theme 2: Standardized asthma clinical practice guidelines and asthma action plan

A total of $24 \%(64 / 282)$ respondents perceived the use of different AAPs or asthma management guidelines being a major issue in childhood asthma care as it might cause confusion to parents/carers. Many believed that 


\begin{tabular}{|c|c|c|c|c|c|c|c|c|c|c|c|}
\hline \multicolumn{2}{|l|}{ 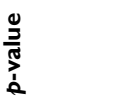 } & 勇 & $\frac{m}{0}$ & $\frac{\frac{0}{x}}{n}$ & $\begin{array}{lllll}1 & 1 & 1 & 1 & 1\end{array}$ & 111 & $\begin{array}{lll}1 & 1 & 1\end{array}$ & $\begin{array}{l}0 \\
\frac{0}{x} \\
\frac{x}{\alpha} \\
0\end{array}$ & oे & $\begin{array}{llll}1 & 1 & 1 & 1\end{array}$ & 11 \\
\hline \multicolumn{2}{|l|}{$\breve{L}$} & $\overline{0}$ & $\stackrel{m}{i}$ & $\overline{\underline{\theta}}$ & $\begin{array}{lllll}1 & 1 & 1 & 1 & 1\end{array}$ & $1 \quad 1 \quad 1$ & $\begin{array}{lll}1 & 1 & 1\end{array}$ & $\overline{\dot{m}}$ & $\stackrel{m}{n}$ & $\begin{array}{llll}1 & 1 & 1 & 1\end{array}$ & 11 \\
\hline \multicolumn{2}{|l|}{ 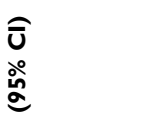 } & $\mid \begin{array}{c}\alpha \\
\alpha \\
o \\
\alpha \\
\alpha \\
\alpha \\
\alpha\end{array}$ & $\begin{array}{l}\widehat{o} \\
\frac{o}{1} \\
\substack{0 \\
0}\end{array}$ & 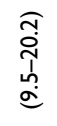 & 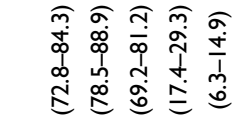 & 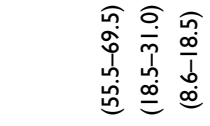 & 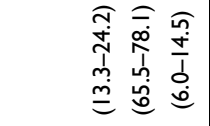 & 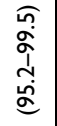 & 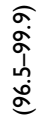 & 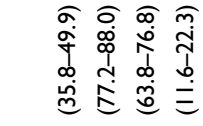 & 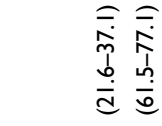 \\
\hline \multicolumn{2}{|l|}{ ๖ } & $\bar{\alpha}$ & 으 & $\stackrel{m}{\dot{I}}$ & 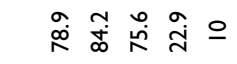 & సิ & $\stackrel{m}{\infty} \bar{i} \stackrel{0}{\circ}$ & $\bar{\infty}$ & $\alpha$ & 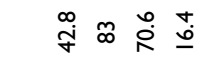 & $\underset{\sim}{\infty}$ ì \\
\hline 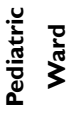 & ఏ & $\underline{g}$ & $\frac{N}{N}$ & $\stackrel{2}{i}$ & 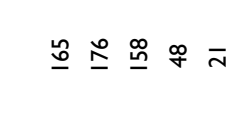 & $\overline{\underline{y}}$ \& & 品 员 & $\stackrel{\infty}{\sim}$ & ర్ & $\infty \underline{\hat{f}} \tilde{\underline{q}}$ & $\bar{\sigma} \alpha$ \\
\hline \multicolumn{2}{|l|}{$\begin{array}{l}\text { ū } \\
\stackrel{\circ}{\circ ٌ}\end{array}$} & $\begin{array}{l}\alpha \\
\alpha \\
o \\
0 \\
\alpha \\
\dot{\alpha} \\
0\end{array}$ & $\begin{array}{l}\widehat{a} \\
\alpha \\
\alpha \\
\alpha \\
o \\
o\end{array}$ & 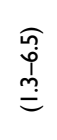 & 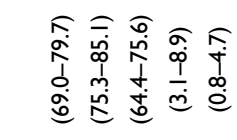 & 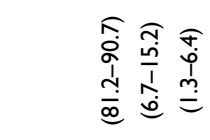 & 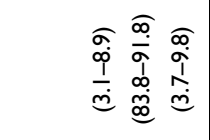 & 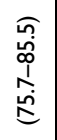 & 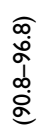 & 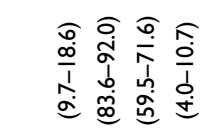 & 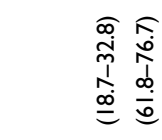 \\
\hline \multicolumn{2}{|l|}{ ○ } & 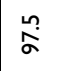 & $\stackrel{\infty}{\infty}$ & $\stackrel{\sim}{m}$ & 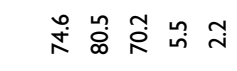 & $\begin{array}{l}+\dot{m} \\
\stackrel{\infty}{\infty}\end{array}$ & 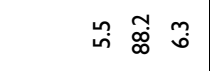 & $\stackrel{\dot{\rho}}{\dot{\infty}}$ & $\stackrel{m}{g}$ & 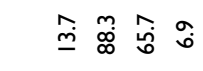 & ڤُ \\
\hline \& & § & $\stackrel{4}{8}$ & 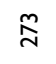 & $n$ & $\stackrel{\sim}{\sim} \stackrel{\sigma}{\sim} \underline{n}$ & $\bar{\sigma} \approx \sim$ & $\underline{n}$ 웜 $=$ & $\frac{m}{N}$ & gे & $\stackrel{m}{\stackrel{\circ}{N} \underline{0}}=$ & 우은 \\
\hline \multicolumn{2}{|l|}{ 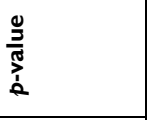 } & $\stackrel{\infty}{\stackrel{\infty}{0}}$ & $\stackrel{n}{\hat{0}}$ & $\frac{0}{0}$ & $\begin{array}{lllll}1 & 1 & 1 & 1 & 1\end{array}$ & $\begin{array}{lll}1 & 1 & 1\end{array}$ & $\begin{array}{lll}1 & 1 & 1\end{array}$ & $\begin{array}{l}\infty \\
0 \\
\frac{1}{x} \\
\stackrel{n}{x}\end{array}$ & $\stackrel{\llcorner}{o}$ & $\begin{array}{llll}1 & 1 & 1 & 1\end{array}$ & 11 \\
\hline \multicolumn{2}{|l|}{ L } & $\hat{o}$ & $\hat{o}$ & $\stackrel{\square}{-}$ & $\begin{array}{lllll}1 & 1 & 1 & 1 & 1\end{array}$ & $1 \quad 11$ & $\begin{array}{lll}1 & 1 & 1\end{array}$ & $\stackrel{+}{+}$ & ò & $\begin{array}{llll}1 & 1 & 1 & 1\end{array}$ & 11 \\
\hline \multicolumn{2}{|l|}{$\begin{array}{l}\text { uิ } \\
\text { ڤ̊ํㅇ }\end{array}$} & 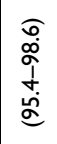 & 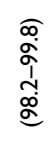 & 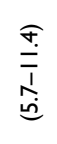 & 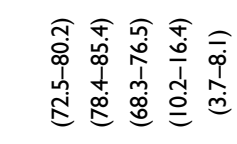 & 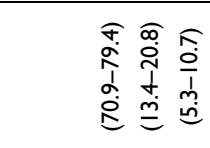 & 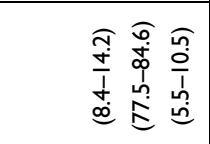 & 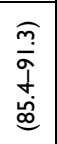 & 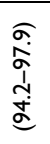 & 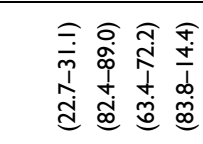 & 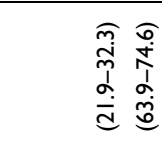 \\
\hline \multicolumn{2}{|l|}{$\circ^{\circ}$} & $\stackrel{m}{\Sigma}$ & $\stackrel{m}{\alpha}$ & $\underset{\infty}{m}$ & 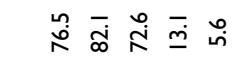 & 芦定 & $\stackrel{+}{=} \frac{m}{\infty} \hat{i}$ & $\begin{array}{l}0 \\
\infty \\
\infty \\
\infty\end{array}$ & $\stackrel{े}{\circ}$ & 今ે & 寉 \\
\hline बٓ & 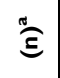 & ồ & $\stackrel{\leftrightarrow \%}{\sigma o}$ & $\stackrel{m}{m}$ & 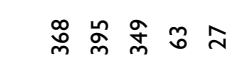 & $\frac{\simeq}{m} 尺 \approx$ & $n$ n & $\overline{\mathcal{Y}}$ & $\bar{y}$ & 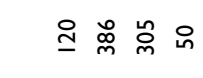 & $\bar{\infty}$ वे \\
\hline \multicolumn{2}{|l|}{ 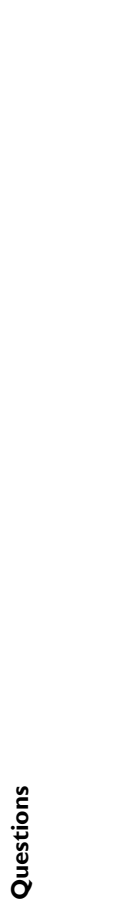 } & 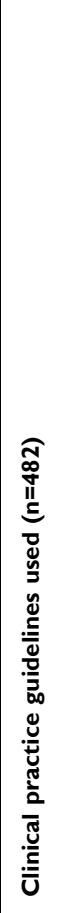 & 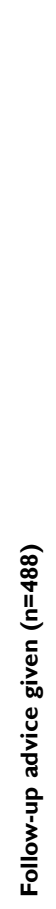 & 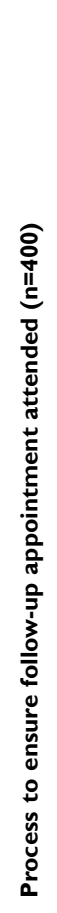 & 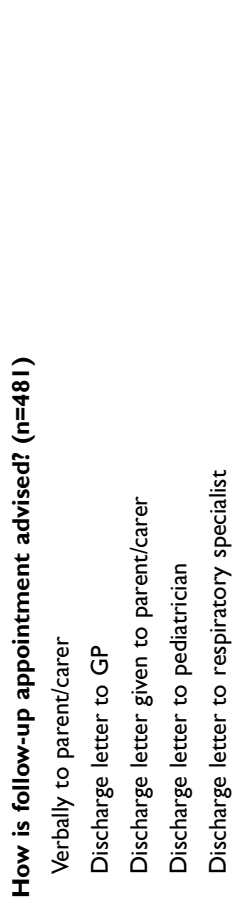 & 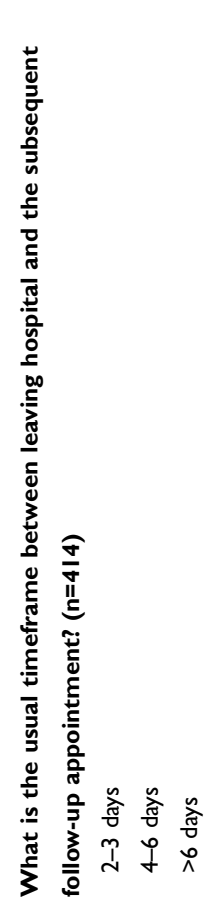 & 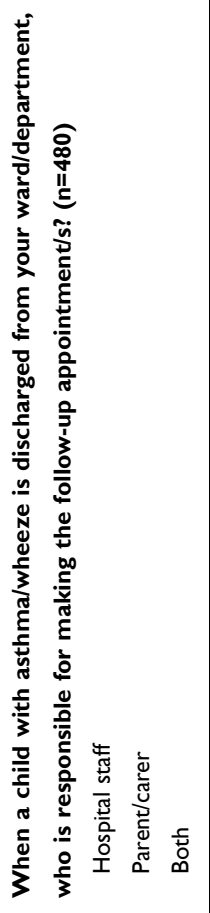 & 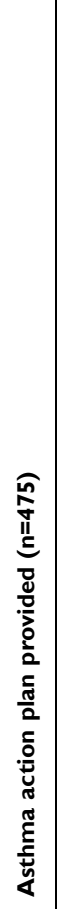 & 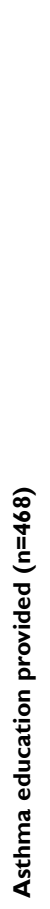 & 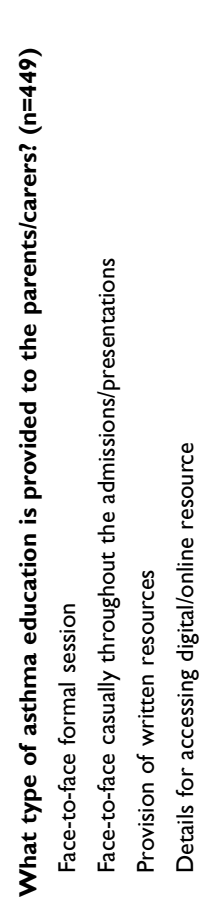 & 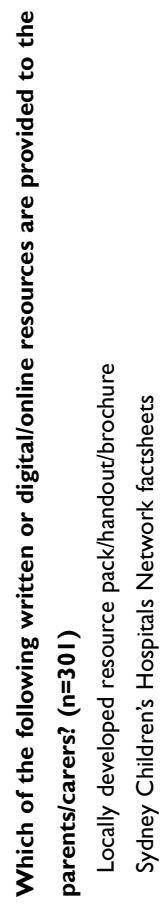 \\
\hline
\end{tabular}




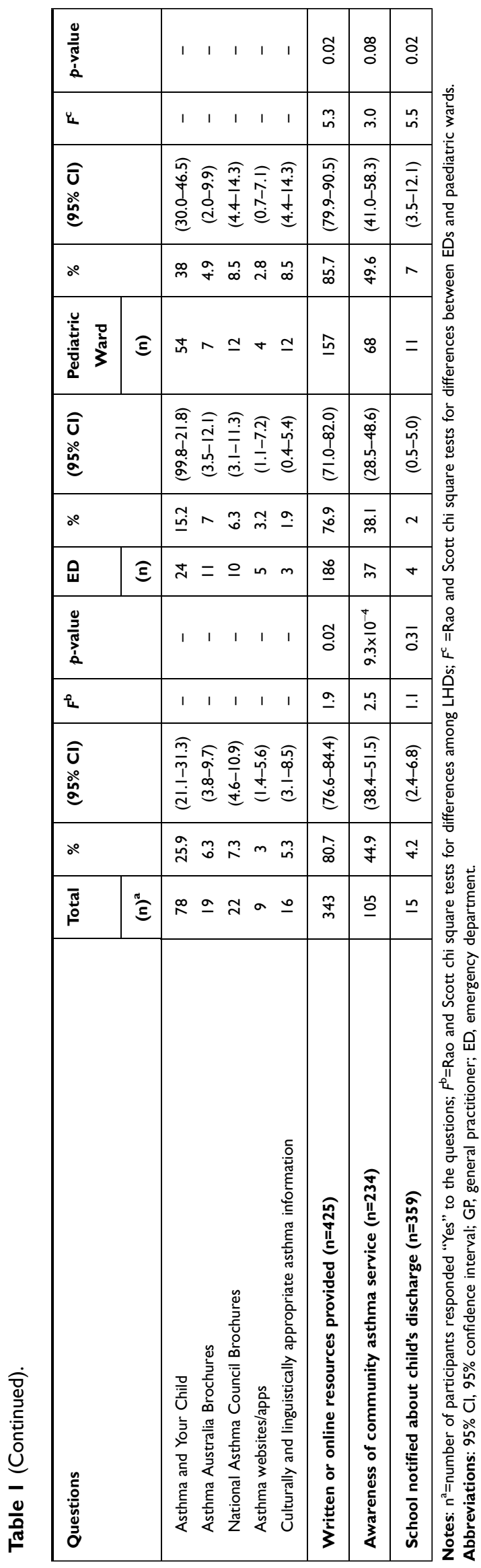

standardization of AAPs and clinical practice guidelines could improve asthma care.

Theme 3: Asthma education

Overall, 23\% (62/282) respondents felt that asthma education was lacking for parents $(n=35)$, schools/childcare services $(\mathrm{n}=15)$ and members of the general community $(\mathrm{n}=5)$. Most believed that asthma education was an essential element in reducing ED presentation and improving asthma management. However, asthma education that was provided in the hospital was largely limited to the use of inhaler devices. They believed it should be broadened to include knowledge of asthma or how to recognize signs of deterioration, etc, and that provision of digitalized resources or applications (apps) could facilitate more effective asthma education.

Theme 4: Communication

Eight (3\%) respondents felt that there existed a gap in communication between hospital staff/healthcare workers and parents/carers. Seventeen $(6 \%)$ recommended better communication between hospitals and schools/childcare services regarding the child's admission and treatment plan which was often left up to the parents or carers. Also, improved communication between hospitals and GPs $(n=11)$ or community services $(n=6)$ was important to maintain continuity of care for the child.

Theme 5: Community asthma care

Of the 282 respondents, $17 \%$ were either unaware of any community service or believed that there was a lack of appropriate community services for children with asthma, especially those in the rural/regional areas, and community nurses (eg, asthma educators or respiratory clinical nurse consultants) were considered the key providers for asthma community services.

Theme 6: Physician training

Approximately 11\% (30/282) of the respondents felt that most GPs were not well equipped to treat paediatric patients with asthma and to improve and maintain consistent asthma care, and believed that GPs should receive regular update and training on current asthma management guidelines.

Theme 7: Asthma funding and resources

Fifteen (5\%) of the staff who responded to the question stated that there were not enough educational resources, time and personnel for asthma education, indicating need for additional resources.

Theme 8: Care coordination

Fourteen $(5 \%)$ respondents believed that there was a need to have some sort of care coordinator to help link 


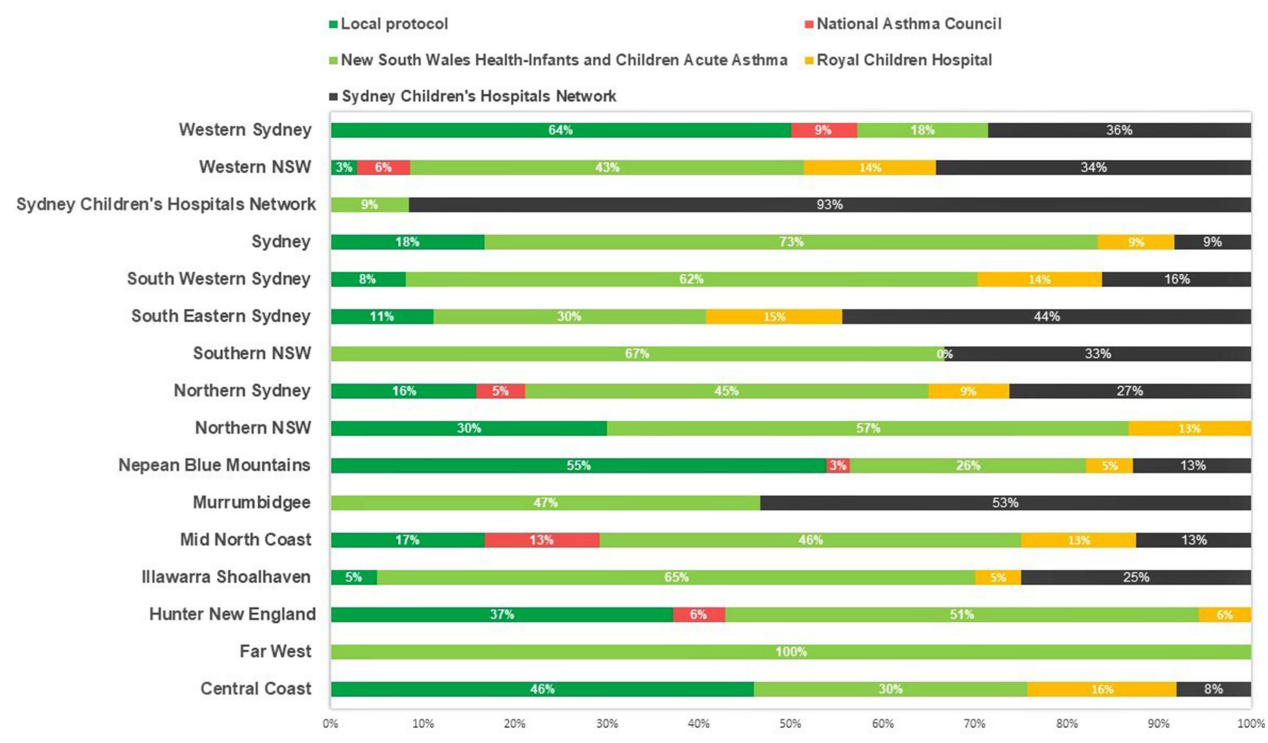

Figure I Clinical practice guidelines used for childhood asthma management in each local health district (LHD).

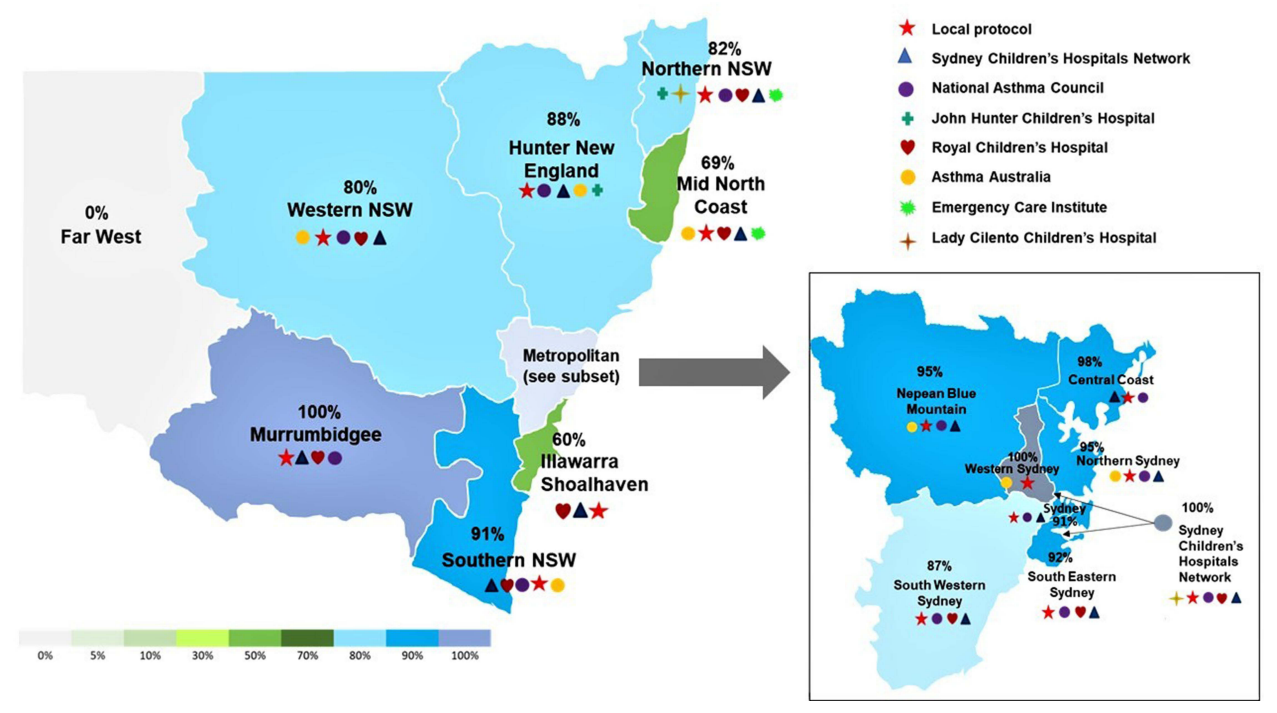

Figure 2 Distribution of asthma action plan utilization in each local health district (LHD).

patients with GPs and facilitate communication between the hospital and GPs or schools/childcare services, which could help to close the loop of missing post-hospitalization follow-up.

\section{Discussion}

This study has demonstrated significant gaps in posthospitalization management pathway and substantial variations in care, including the use of asthma clinical practice guidelines and AAPs within and across different health districts of New South Wales, as well as between ED and paediatric ward, in managing asthma for children. Previous studies on barriers to successful asthma management have been largely based on the perspectives of patients or primary care providers. ${ }^{18,27,28}$ In this study, we explored the gaps in asthma care from the viewpoints of the acute care providers.

Since the introduction of the first asthma guidelines in $1989,{ }^{29}$ more than a dozen asthma clinical practice 


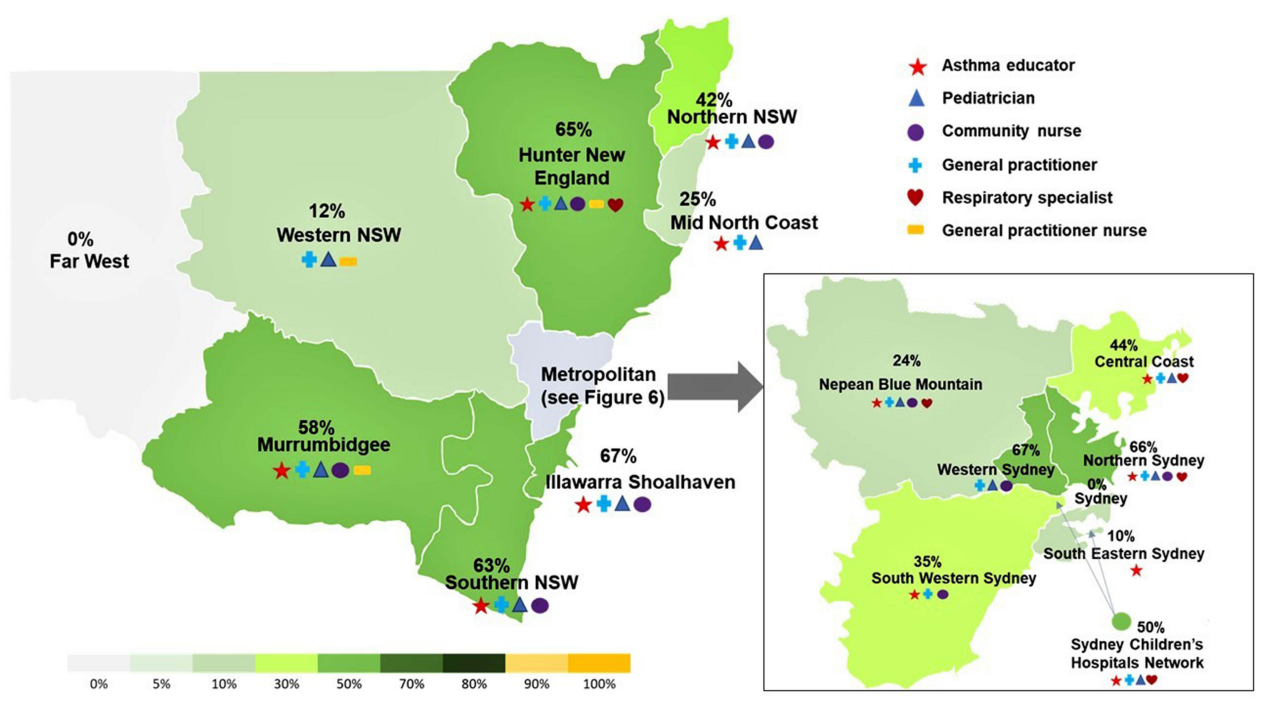

Figure 3 Distribution of community services available for children with asthma in each local health district (LHD).

guidelines have been developed to help practitioners in the diagnosis, treatment and management of asthma. However, the management of asthma in line with evidence-based guidelines remains suboptimal. ${ }^{30-32}$ In our survey, the choice of which guidelines to follow differed greatly within and across LHDs. Such discrepancies not only lead to variation of care but also create confusion about the best treatment option for patients. ${ }^{33,34}$ Although barriers to guideline adherence by doctors have been linked to their knowledge and attitude towards guidelines, ${ }^{28,35}$ lack of consensus among different guidelines may contribute to health professionals' reluctance to follow the recommendations. ${ }^{36}$ In a review of seven national and international asthma clinical practice guidelines, Bakel et $\mathrm{al}^{34}$ found that there was fairly low agreement among these guidelines with $k$ score of 0.03 (95\% CI, -0.01 to 0.10 ).

It is widely accepted that asthma self-management education is critical to optimal management of asthma. ${ }^{37}$ Lack of education about asthma has been associated with frequent $\mathrm{ED}$ visits and uncontrolled symptoms. ${ }^{38}$ However, in-depth asthma education is time-consuming and often not possible in EDs or hospital settings. As shown in this study, asthma education provided in hospital was often limited to asthma device techniques and seldom involved topics such as basic knowledge of asthma, asthma control, and importance of regular medical review. Such findings were consistently reported across LHDs, and coincided with a previous report on parental perspective of barriers to asthma control, which showed half of the parents/carers reported that they did not feel they knew much about asthma triggers and more than one-third reported that they did not have enough information about their child's asthma. ${ }^{18}$

With the advancement in information technology, there is growing interest in the use of internet or digital media in asthma education or self-management support. A systematic review of 29 studies supported the benefit of digital interventions in improving knowledge, improving quality of life and increasing medication adherence for patients with asthma. ${ }^{39}$ Our previous work showed that selfdirected training through an online multimedia eBook, "Asthma First Aid Management in Schools eBook" developed by the Aiming for Asthma Improvement in Children (AAIC), was associated with a significant improvement in knowledge and self-confidence in school staff. ${ }^{14}$ However, the present findings suggested that digital resources had been underutilised in our health system for asthma education (ie, only $3 \%$ of the staff indicated that links to online asthma apps or websites were provided to parents during asthma education).

Lack of community care for asthma emerged as key theme from this study, with $17 \%$ of the respondents perceiving it as a major gap in asthma care for children. Despite significant variability between LHDs, the majority of participants indicated that they were not aware of any community services for children with asthma within their local health districts.

In a review of 223 asthma intervention programs, Clark et $\mathrm{al}^{40}$ concluded that being "community-centred" 


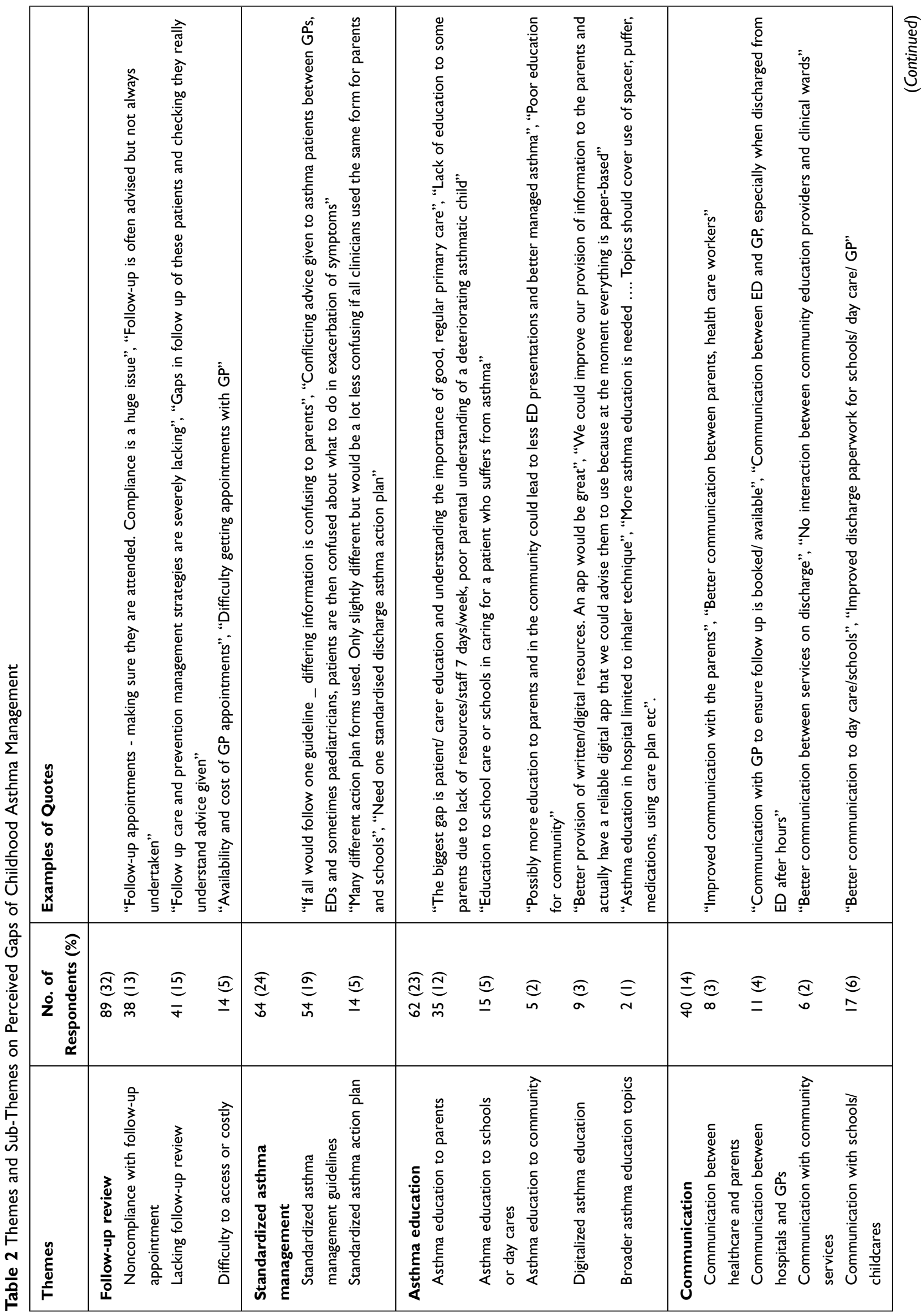




\begin{tabular}{|c|c|c|c|c|}
\hline 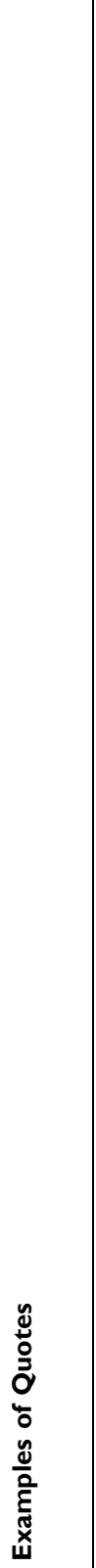 & 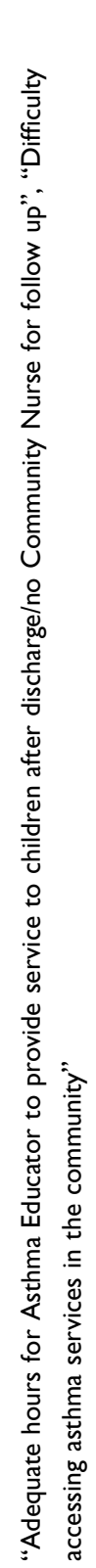 & 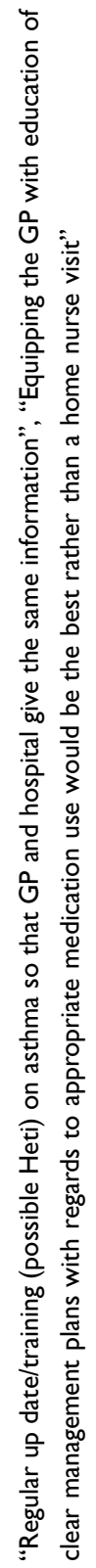 & 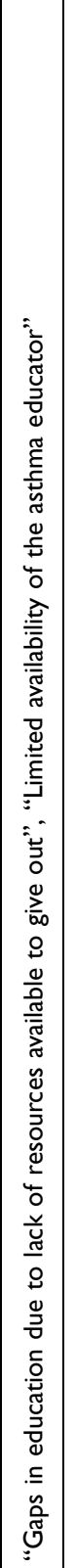 & 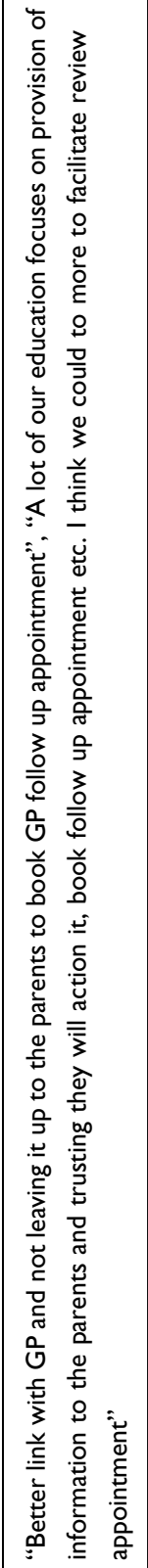 \\
\hline 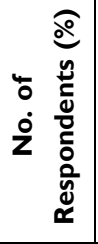 & $\underset{\substack{q\\
}}{\widehat{E}}$ & $\begin{array}{l}\widehat{\equiv} \\
\text { 品 }\end{array}$ & $\begin{array}{l}\widehat{\underline{n}} \\
\underline{n}\end{array}$ & 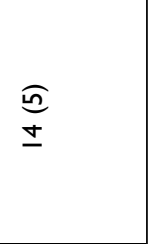 \\
\hline 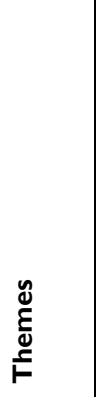 & 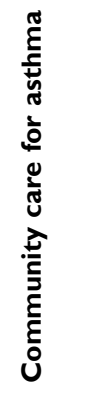 & 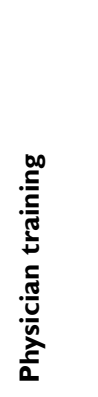 & 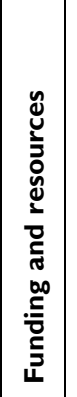 & 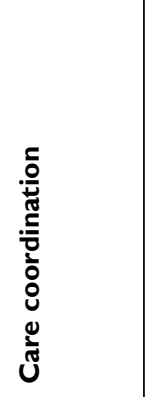 \\
\hline
\end{tabular}

was a key factor for a successful asthma program with positive asthma outcomes. This is in line with our recent meta-analysis of 21 community-based studies on multicomponent interventions, where ED visits and hospitalizations were reduced by up to $75 \%$ in children with asthma. ${ }^{41}$ Most of these community-based interventions involved reaching out to patients and families in their homes by trained community health workers or nurses for provision of asthma self-management education and assessment of potential asthma triggers within the home environment. ${ }^{9,42}$ Some of them also facilitated the communication between hospitals and primary care providers, ${ }^{9}$ schools or other social services, which is lacking in the current system in New South Wales.

Findings of this study also revealed a departmental discrepancy in asthma education, use of AAP and follow-up advice for children discharged from EDs vs paediatric wards. It was unclear why patients discharged from EDs were more likely to be advised with a shorter follow-up timeframe ( $\leq 3$ days) than those admitted as inpatients, ie, nearly $37 \%$ of the ward staff reported $a \geq 4$ days follow-up recommendation. A study of 30,000 patients had shown that early post-hospitalization follow-up was critical in preventing hospital readmissions, with a reduction of about 23$25 \% .{ }^{43}$ It is possible that the discrepancies found between EDs and the wards are due to the fact that patients discharged from ED are not as stable as those discharged from the wards, and hence, requiring earlier follow-up to monitor their conditions. Additionally, due to overwhelming workload and time constraint within EDs, it is likely that asthma education and AAP were provided less frequently in EDs than in the wards. ${ }^{44}$

This study is subject to several limitations. First, although the sample size was reasonably large, the number of participants per LHD varied greatly depending on the number of hospitals and staff available at each LHD. Nevertheless, our study population had extensive coverage including all the hospitals with paediatric intake across LHDs in New South Wales. Second, the overall response rate was low; however, it was within the expected level of web-based surveys. ${ }^{45}$ Third, since this study was undertaken in New South Wales, our findings may not be generalizable to other states of Australia with different local healthcare policies. However, this study has highlighted important gaps in transition of care from hospital to the community for children with asthma. There are very few published data on the gaps of post-discharge care paediatric asthma. Our study is novel and adds to the body of 
evidence for future investigations on post-discharge childhood asthma in countries with comparable healthcare system. Finally, our study assessed care gaps in childhood asthma management from the perspectives of hospital staff only and further studies are required to include the viewpoints of primary care providers and parents/carers.

\section{Conclusions}

Despite significant advancement in therapeutic treatment for asthma, it remains one of the leading respiratory causes of ED visits and hospital admissions for Australian children. In this study, we identified marked variations in postdischarge asthma care and management for children within different health jurisdictions, different hospitals in same jurisdiction and different departments of same hospital in New South Wales, highlighting the lack of standardization of care for children with asthma.

\section{Abbreviations}

AAP, asthma action plan; ED, emergency department; LHD, Local Health District; DALY, disability-adjusted life-year; GINA, Global Initiative for Asthma; GP, general practitioner; 95\% CI, 95\% confidence interval; AAIC, Aiming for Asthma Improvement in Children.

\section{Data Sharing Statement}

Access to the dataset analysed during the current study is not permitted without the express permission of the approving Human Research Ethics Committees. There are no additional data available.

\section{Acknowledgment}

The authors would like to thank Sydney Children's Hospital Foundation and Rotary Club of Sydney Cove for their continued support in our research endeavours. This work was supported by the Rotary Club of Sydney Cove. The funding organization had no role in the study design, analyses or drafting of the manuscript. We are also grateful to Asthma Australia for their ongoing support with our asthma researches. $\mathrm{NH}$ is funded through NHMRC research fellowship (APP115646). We would also like to thank all the Nurse Unit Managers, Heads of Department, Clinical Directors and administrative staff from the ED and paediatric units of the participating hospitals for their assistance with the survey distributions.

\section{Disclosure}

The authors declare no conflicts of interest.

\section{References}

1. WHO. Asthma. WHO; 2020. Available from: www.who.int/newsroom/fact-sheets/detail/asthma. Accessed February 23, 2020.

2. AIHW. Asthma Hospitalisations in Australia 2010-11. Cat No. ACM 27.2013. 2013 ed. Canberra: AIHW; 2013.

3. Khan FI, Reddy RC, Baptist AP. Pediatric Dyspnea Scale for use in hospitalized patients with asthma. J Allerg Clin Immunol. 2009;123 (3):660-664. doi:10.1016/j.jaci.2008.12.018

4. Mallol J, Garcia-Marcos L, Sole D, Brand P; Group ES. International prevalence of recurrent wheezing during the first year of life: variability, treatment patterns and use of health resources. Thorax. 2010;65 (11):1004-1009. doi:10.1136/thx.2009.115188

5. Uijen JH, Schellevis FG, Bindels PJ, Willemsen SP, van der Wouden JC. Low hospital admission rates for respiratory diseases in children. $B M C$ Fam Pract. 2010;11:76. doi:10.1186/1471-2296-11-76

6. Bloomberg GR, Trinkaus KM, Fisher EB, Musick JR, Strunk RC. Hospital readmissions for childhood asthma: a 10-year metropolitan study. Am J Respir Crit Care Med. 2003;167(8):1068-1076. doi:10.1164/rccm.2201015

7. Asthma Australia. Asthma statistics and facts. Asthma Australia; 2021. Available from: https://asthma.org.au/about-asthma/understand ing-asthma/statistics/. Accessed January 27, 2021.

8. GINA Committee. Global initiative for asthma: pocket guide for asthma management; 2017. Available from: https://ginasthma.org/. Accessed August 11, 2020.

9. Mansfield C, Viswanathan M, Woodell C, et al. Outcomes from a cross-site evaluation of a comprehensive pediatric asthma initiative incorporating translation of evidence-based interventions. Health Promot Pract. 2011;12(6Suppl 1):34S-51S. doi:10.1177/1524839911415665

10. Findley S, Rosenthal M, Bryant-Stephens T, et al. Community-based care coordination: practical applications for childhood asthma. Health Promot Pract. 2011;12(6Suppl 1):52S-62S. doi:10.1177/1524839911404231

11. Kennedy S, Bailey R, Jaffee K, et al. Effectiveness of evidence-based asthma interventions. Pediatrics. 2017;139(6):e20164221. doi:10.1542/peds.2016-4221

12. Lara M, Ramos-Valencia G, Gonzalez-Gavillan JA, et al. Reducing quality-of-care disparities in childhood asthma: la Red de Asma Infantil intervention in San Juan, Puerto Rico. Pediatrics. 2013;131 (Suppl 1):S26-37. doi:10.1542/peds.2012-1427d

13. Park HJ, Byun MK, Kim HJ, et al. Regular follow-up visits reduce the risk for asthma exacerbation requiring admission in Korean adults with asthma. Allergy Asthma Clin Immunol. 2018;14:29. doi:10.1186/ s13223-018-0250-0

14. Francis S, Gray M, Burns C, Briggs N, Homaira N, Jaffe A. Role of technology in improving knowledge and confidence in asthma management in school staff. J Asthma. 2020;57(4):452-457. doi:10.1080/ 02770903.2019.1571087

15. Langton CR, Hollenbach JP, Simoneau T, Cloutier MM. Asthma management in school: parents' and school personnel perspectives. J Asthma. 2020;57(3):295-305. doi:10.1080/02770903.2019.156 8455

16. NSW Government. Local health districts and specialty networks. NSW Government; 2018. Available from: https://www.health.nsw. gov.au/lhd/pages/default.aspx. Accessed January 6, 2021.

17. Ministry of Health NSW. Infants and Children: Acute Management of Asthma Clinical Practice Guideline. NSW: NSW Kids and Families; 2012.

18. Haby MM, Powell CV, Oberklaid F, Waters EB, Robertson CF. Asthma in children: gaps between current management and best practice. $J$ Paediatr Child Health. 2002;38(3):284-289. doi:10.1046/j.1440-1754.2002.00814.x

19. Trent CA, Zimbro KS, Rutledge CM. Barriers in asthma care for pediatric patients in primary care. J Pediatr Health Care. 2015;29 (1):70-79. doi:10.1016/j.pedhc.2014.07.002 
20. Heiner MM. Key barriers to optimal management of adult asthma in Australia: physician and patient perspectives. Curr Med Res Opin. 2007;23(8):1799-1807. doi:10.1185/030079907X210714

21. Price C, Agarwal G, Chan D, et al. Large care gaps in primary care management of asthma: a longitudinal practice audit. BMJ Open. 2019;9(1):e022506. doi:10.1136/bmjopen-2018-022506

22. Rao JNK, Scott AJ. The analysis of categorical data from complex sample surveys: chi squared tests for goodness of fit and independence in two-way tables. J Am Stat Assoc. 1981;76:221-230. doi:10.1080/01621459.1981.10477633

23. Rao JN, Scott AJ. A simple method for the analysis of clustered binary data. Biometrics. 1992;48(2):577-585. doi:10.2307/2532311

24. Clopper CJ, Pearson ES. The use of confidence or fiducial limits illustrated in the case of the binomial. Biometrika. 1934;26:404-413. doi:10.1093/biomet/26.4.404

25. Braun V, Clarke V. Using thematic analysis in psychology. Qual Res Psychol. 2006;3:77-101. doi:10.1191/1478088706qp063oa

26. Taherdoost $\mathrm{H}$. What is the best response scale for survey and questionnaire design; review of different lengths of rating scale/attitude scale/likert scale. Int J Acad Res Manag. 2019;8(1):1-10.

27. Goeman DP, Hogan CD, Aroni RA, et al. Barriers to delivering asthma care: a qualitative study of general practitioners. Med $J$ Aust. 2005;183(9):457-460. doi:10.5694/j.1326-5377.2005. tb07122.x

28. Gagne ME, Boulet LP. Implementation of asthma clinical practice guidelines in primary care: a cross-sectional study based on the knowledge-to-action cycle. J Asthma. 2018;55(3):310-317. doi:10.1080/02770903.2017.1323919

29. Woolcock A, Rubinfeld AR, Seale JP, et al. Thoracic society of Australia and New Zealand. Asthma management plan, 1989. Med $J$ Aust. 1989;151(11-12):650-653. doi:10.5694/j.1326-5377.1989. tb139640.x

30. Collins S, Beilby J, Fardy J, Burgess T, Johns R, Booth B. The national asthma audit. Bridging the gap between guidelines and practice. Aust Fam Physician. 1998;27(10):907-913.

31. Chapman KR, Hinds D, Piazza P, et al. Physician perspectives on the burden and management of asthma in six countries: the Global Asthma Physician Survey (GAPS). BMC Pulm Med. 2017;17 (1):153. doi:10.1186/s12890-017-0492-5

32. Cloutier MM, Salo PM, Akinbami LJ, et al. Clinician agreement, self-efficacy, and adherence with the guidelines for the diagnosis and management of asthma. J Allergy Clin Immunol Pract. 2018;6 (3):886-894 e884. doi:10.1016/j.jaip.2018.01.018

33. Braido F. Failure in asthma control: reasons and consequences. Scientifica (Cairo). 2013;2013:549252. doi:10.1155/2013/549252
34. Bakel LA, Hamid J, Ewusie J, et al. International variation in asthma and bronchiolitis guidelines. Pediatrics. 2017;140(5):e20170092. doi:10.1542/peds.2017-0092

35. Baiardini I, Braido F, Bonini M, Compalati E, Canonica GW. Why do doctors and patients not follow guidelines? Curr Opin Allergy Clin Immunol. 2009;9(3):228-233. doi:10.1097/ACI.0b013e32832b4651

36. Potter PC. Current guidelines for the management of asthma in young children. Allergy Asthma Immunol Res. 2010;2(1):1-13. doi:10.4168/ aair.2010.2.1.1

37. Krieger J, Song L, Philby M. Community health worker home visits for adults with uncontrolled asthma: the HomeBASE Trial randomized clinical trial. JAMA Intern Med. 2015;175(1):109-117. doi:10.1001/jamainternmed.2014.6353

38. Al-Muhsen S, Horanieh N, Dulgom S, et al. Poor asthma education and medication compliance are associated with increased emergency department visits by asthmatic children. Ann Thorac Med. 2015;10 (2):123-131. doi:10.4103/1817-1737.150735

39. Morrison D, Wyke S, Agur K, et al. Digital asthma self-management interventions: a systematic review. J Med Internet Res. 2014;16(2): e51. doi:10.2196/jmir.2814

40. Clark N, Lachance L, Milanovich AF, Stoll S, Awad DF. Characteristics of successful asthma programs. Public Health Rep. 2009;124(6):797-805. doi:10.1177/003335490912400606

41. Chan M, Gray M, Burns C, et al. Community-based interventions for childhood asthma using comprehensive approaches: a systematic review and meta-analysis. Allergy Asthma Clin Immunol. 2021;17 (1):19. doi:10.1186/s13223-021-00522-9

42. Crocker DD, Kinyota S, Dumitru GG, et al. Effectiveness of home-based, multi-trigger, multicomponent interventions with an environmental focus for reducing asthma morbidity: a community guide systematic review. Am J Prev Med. 2011;41(2 Suppl 1):S5-32. doi:10.1016/j.amepre.2011.05.012

43. Hernandez AF, Greiner MA, Fonarow GC, et al. Relationship between early physician follow-up and 30-day readmission among Medicare beneficiaries hospitalized for heart failure. JAMA. 2010;303 (17):1716-1722. doi:10.1001/jama.2010.533

44. Petre B, Margat A, Servotte JC, Guillaume M, Gagnayre R, Ghuysen A. Patient education in the emergency department: take advantage of the teachable moment. Adv Health Sci Educ Theory Pract. 2020;25(2):511-517. doi:10.1007/s10459-019-09893-6

45. Yun GW, Trumbo CW. Comparative response to a survey executed by post, e-mail, \& web form. J Comp Mediated Com. 2000;6.

\section{Publish your work in this journal}

The Journal of Asthma and Allergy is an international, peer-reviewed open-access journal publishing original research, reports, editorials and commentaries on the following topics: Asthma; Pulmonary physiology; Asthma related clinical health; Clinical immunology and the immunological basis of disease; Pharmacological interventions and new therapies. The manuscript management system is completely online and includes a very quick and fair peer-review system, which is all easy to use. Visit http://www.dovepress.com/testimonials.php to read real quotes from published authors. 